\section{KẾT LUÂN}

Tái tạo tuyến vú một thì bằng túi độn cho kết quả thẩm mỹ tốt, có sự suy giảm tính thẩm mỹ theo thời gian nhưng ở mức chấp nhận được. Trong nghiên cứu của chúng tôi, không tìm thấy mối liên quan giữa điểm thẩm mỹ và tuổi, BMI, thể tích túi; biến chứng sớm, hoá chất bổ trợ. Ớ nhóm bệnh nhân có chỉ định xạ trị bổ trợ sau phẫu thuật và nhóm có biến chứng bao xơ quanh túi, kết quả thẩm mỹ thu được là thấp hơn có ý nghĩa so với nhóm không cần xạ trị, không có bao xơ.

\section{TÀI LIÊU THAM KHẢO}

1. Sung H., Ferlay J., Siegel R.L., et al. (2021). Global Cancer Statistics 2020: GLOBOCAN Estimates of Incidence and Mortality Worldwide for 36 Cancers in 185 Countries. CA Cancer J Clin, 71(3), 209-249.

2. Tóth 'D., Varga Z., Sebő É., et al. (2016). Predictive Factors for Positive Margin and the Surgical Learning Curve in Non-Palpable Breast Cancer After Wire-Guided Localization Prospective Study of 214 Consecutive Patients. Pathol Oncol Res, 22(1), 209-215.

3. Carlson G.W., Losken A., Moore B., et al, (2001). Results of immediate breast reconstruction after skin-sparing mastectomy. Ann
Plast Surg, 46(3), 222-228

4. Mioton L.M., Seth A., Gaido J., et al. (2014). Tracking the aesthetic outcomes of prosthetic breast reconstructions that have complications. Plast Surg (Oakv), 22(2), 70-74.

5. Clough K.B., O'Donoghue J.M., Fitoussi A.D., et al. (2001). Prospective evaluation of late cosmetic results following breast reconstruction: I. Implant reconstruction. Plast Reconstr Surg, 107(7), 1702-1709.

6. McCarthy C.M., Mehrara B.J., Riedel E., et al. (2008). Predicting complications following expander/implant breast reconstruction: an outcomes analysis based on preoperative clinical risk. Plast Reconstr Surg, 121(6), 1886-1892.

7. Seth A.K. and Cordeiro P.G. (2020). Stability of Long-Term Outcomes in Implant-Based Breast Reconstruction: An Evaluation of 12-Year Surgeonand Patient-Reported Outcomes in 3489 Nonirradiated and Irradiated Implants. Plast Reconstr Surg, 146(3), 474-484.

8. Thomssen C., Balic M., Harbeck $N_{\text {. }}$ et al. (2021). St. Gallen/Vienna 2021: A Brief Summary of the Consensus Discussion on Customizing Therapies for Women with Early Breast Cancer. Breast Care, 16(2), 135-143.

9. Ramon $Y_{\text {., Ulmann }} Y_{\text {., Moscona }} R_{\text {., et al. }}$ (1997). Aesthetic results and patient satisfaction with immediate breast reconstruction using tissue expansion: a follow-up study. Plast Reconstr Surg, 99(3), 686-691.

\title{
KHẢO SÁT LIÊN QUAN GIỮA BIẾN THỂ ABCG2 Q141K VÀ ACID URIC Ở NGƯỜI TRƯỞNG THÀNH
}

\author{
Lý Bảo Ngọc ${ }^{1}$, Lê Gia Hoàng Linh ${ }^{2}$, Đỗ Đức Minh ${ }^{2}$
}

\section{TÓM TẮT}

Muc tiêu: Nồng độ acid uric máu chịu ảnh hưởng của yểu tố di truyền. Nghiên cứu của chúng tôi nhằm khảo sát liên quan giữa điểm đa hình đơn nucleotide Q141K của gen $A B C G 2$ và nồng độ acid uric máu ở người Việt Nam trưởng thành. Đối tượng và phương pháp: Thiết kế nghiên cứu mô tả loạt ca, 150 đối tượng được khảo sát biến thể Q141K của $A B C G 2$ bằng phương pháp giải trình tự Sanger. Kết quả: Tỉ lệ biến thể Q141K của $A B C G 2$ ở người Việt Nam trưởng thành là 54\%. Q141K không có mối liên quan với nông đô acid uric máu ở người Việt Nam trưởng thành trên các mô hình phân tích. Q141K có xu hướng tăng nồng độ acid uric máu. Kết luận: Biến thể Q141K không liên quan nồng độ acid uric máu ở người Việt Nam trưởng

\footnotetext{
${ }^{1}$ Đại học Y khoa Phạm Ngọc Thạch

Eai hoc Y Dước TP.HCM

Chịu trách nhiệm chính: Đỗ Đức Minh

Email: ducminh@ump.edu.vn

Ngày nhận bài: 14.9.2021

Ngày phản biên khoa họ: 10.11.2021

Ngày duyệt bài: 18.11.2021
}

thành. Tư khóa: nồng độ acid uric máu, điểm đa hình đơn nucleotide, Q141K, gen ABCG2.

\section{SUMMARY \\ THE ASSOCIATION BETWEEN ABCG2 Q141K VARIANT AND SERUM URIC ACID CONCENTRATION IN ADULTS}

Background: Serum uric acid concentration is influenced by genetic factor. The present study aimed to investigate the association between ABCG2 Q141K variant and serum uric acid concentration in Vietnamese adults. Objectives and methods: In this case series study, 150 participants were enrolled and genotyped for ABCG2 Q141K variant using Sanger sequencing. Results: Frequency of ABCG2 Q141K variant was $54 \%$ in Vietnamese adults. Q141K was not significantly associated with serum uric acid concentration in Vietnamses adults by statistical models. Q141K inclined to elevate serum uric acid level. Conclusion: The association between ABCG2 Q141K variant and serum uric acid concentration is not established in Vietnamese adults.

Keywords: serum uric acid concentration, single nucleotide polymorphism, Q141K, ABCG2 gene. 


\section{I. ĐĂT VẤN ĐỀ}

Acid uric là sản phẩm chuyển hóa của purines, bao gồm purine nội sinh và purine ngoại sinh. Nồng độ acid uric máu được giữ ổn định nhờ sự cân bằng giữa quá trình tổng hợp và quá trình bài xuất acid uric. Rối loạn nồng độ acid uric máu được nhiều nghiên cứu báo cáo tăng gánh nặng bệnh tật cho nhiều quốc gia, có liên quan bệnh đồng mắc như bệnh tim mạch, bệnh thận mạn, hội chứng chuyển hóa, đái tháo đường típ $2^{(1)}$. Nồng độ acid uric máu chịu tác động của các yếu tố tuổi tác, giới tính, chủng tộcc, lối sống và yếu tố di truyền ${ }^{(2)}$.

$A B C G 2$ là gen nằm trên nhiễm sắc thể số 4 , mã hóa cho protein $A B C G 2$, nằm trên màng đỉnh tế bào biểu mô ống lượn gần, tế bào biểu mô ruột, tế bào gan, thực hiện chức năng bài xuất acid uric (3). Nhiều nghiên cứu gần đây cho thấy giảm biểu hiện $A B C G 2$ do các biến thể của ABCG2 có liên quan nồng độ acid uric máu ở các chủng tộc trên thế giới. Trong đó, biến thể $\mathrm{ABCG} 2 \mathrm{Q} 141 \mathrm{~K}$ (rs2231142), nằm tại exon 5 , là biến thể sai nghĩa (c.421 C>A), được báo cáo liên quan nguy cơ tăng acid uric máu, có tần số phổ biến ở dân số Châu Á(4). Vì vậy, chúng tôi tiến hành nghiên cứu này nhằm khảo sát liên quan giữa biến thể $A B C G 2$ Q141K và nồng độ acid uric máu ở người Việt Nam trưởng thành.

\section{II. ĐỐI TƯỢNG VÀ PHƯƠNG PHÁP NGHIÊN CỨU}

1. Đối tượng nghiên cứu: đối tượng chọn vào thỏa các tiêu chuẩn cu thể sau:

\section{Tiêu chuẩn chơn mẩu}

- Người trưởng thành (từ đủ 18 tuổi trở lên)

- Đồng ý tham gia nghiên cứu

\section{Tiêu chuân loai trừ}

- Sử dụng thuốc hoặc mắc bệnh lý cấp tính, mạn tính ảnh hưởng nồng độ acid uric máu.

- Đang trong thai kỳ hoặc đang trong thời gian 12 tuần hậu sản

\section{Phương pháp nghiên cứu}

2.1 Thiết kế nghiên cứu: mô tả loạt ca

2.2 Cỡ mẫu: 150 đối tượng

2.3 Phương pháp thực hiện: Tất cả đối tượng tham gia nghiên cứu được thu thập thông tin nhân chủng học, sinh hiệu, tiền căn và nồng độ acid uric máu. Mỗi đối tượng sẽ được thu thập $2 \mathrm{ml}$ máu tĩnh mạch chống đông bởi EDTA, để xác định biến thể ABCG2 Q141K. Genomic DNA của các tế bào bạch cầu từ mẫu máu sẽ được tách chiết bằng bộ kit GeneJet whole blood genomic DNA purification (Thermo Scientific, $M y ̃)$. Phản ứng $P C R$, khuếch đại $A B C G 2$, có sử dụng: bộ mồi được thiết kế cho điểm đa hình; TaKaRa Tag HotStart Polymerase (Takara, Nhật Bản); máy Mastercycler@Pro S (Eppendorf, Đức). Sản phẩm PCR được kiểm tra bằng kỹ thuật điện di trên gel agarose $2 \%$ và nhuộm bằng Diamond Nucleic Acid Dye (Promega, Mỹ), sau đó, được tinh sạch bằng Exosap-IT glycerol solution (Affymetrix, Mỹ) và thực hiện phản ứng cycle sequencing với BigDye Terminator v3.1 Cycle Sequencing kit (Applied Biosystems, Mỹ). Trình tự $D N A$ được đọc bằng máy $A B I 3130$ Genetic Analyzer với POP-7 polymer, capillary 50 $\mathrm{cm}$ (Applied Biosystems, Mỹ). Kết quả giải trình tự DNA được phân tích bằng phần mềm CLC Main Workbench. Toàn bộ quy trình giải trình tự gen đã được tối ưu hóa qua các nghiên cứu trước đây $(5,6,7)$.

2.4 Phân tích thống kê: $x^{2}$ test được dùng cho biến định tính. Mann-Whitney test, KruskalWallis test dùng cho biến định lượng. Mối liên quan giữa $A B C G 2$ Q141K và nồng độ acid uric máu được đánh giá theo các mô hình gen: cộng gộp, lặn, trội, đồng trội( ${ }^{(8)}$. Khác biệt có ý nghĩa thống kê khi giá trị $\mathrm{p}<0.05$.

2.5 Vấn đề đạo đức trong nghiên cứu: Đề tài nghiên cứu đã được chấp thuận của Hội đồng đạo đức trong nghiên cứu $Y$ sinh học Đại học $Y$ Dược Thành phố Hồ Chí Minh với quyết định số 548/HĐĐĐ-ÐHYD ngày 14 tháng 9 năm 2020.

\section{KẾT QUẢ NGHIÊN CỨU}

1. Đặc điểm đối tượng nghiên cứu. Nồng độ acid uric máu có sự khác biệt có ý nghĩa thống kê theo giới tính $(p<0,05)$.

\begin{tabular}{|c|c|c|c|c|}
\hline \multicolumn{5}{|c|}{ Đặc điếm (N=150) } \\
\hline & \multicolumn{3}{|c|}{$38 / 112$} & \\
\hline & $\begin{array}{c}\text { Giá trị } \\
\text { trung vị }\end{array}$ & $\begin{array}{c}\text { Khoảng 25 } \\
\mathbf{7 5}^{\text {th }}\end{array}$ & Min - Max & $\begin{array}{c}\text { Giá trị } \\
\text { p }\end{array}$ \\
\hline Tuối (năm) & 35.00 & $31.00-40.00$ & $23.00-60.00$ & \\
\hline BMI $\left(\mathrm{kg} / \mathrm{m}^{2}\right)$ & 22.30 & $19.80-24.00$ & $16.20-34.30$ & \\
\hline Huyết áp tâm thu $(\mathrm{mmHg})$ & 118.50 & $105.00-126.80$ & $90.00-148.00$ & \\
\hline Huyết áp tâm trương $(\mathrm{mmHg})$ & 72.00 & $65.00-80.00$ & $60.00-113.00$ & \\
\hline Nồng độ acid uric máu $(\mathrm{mg} / \mathrm{dl})$ & 5.12 & $4.39-5.83$ & $3.17-7.60$ & \\
\hline
\end{tabular}




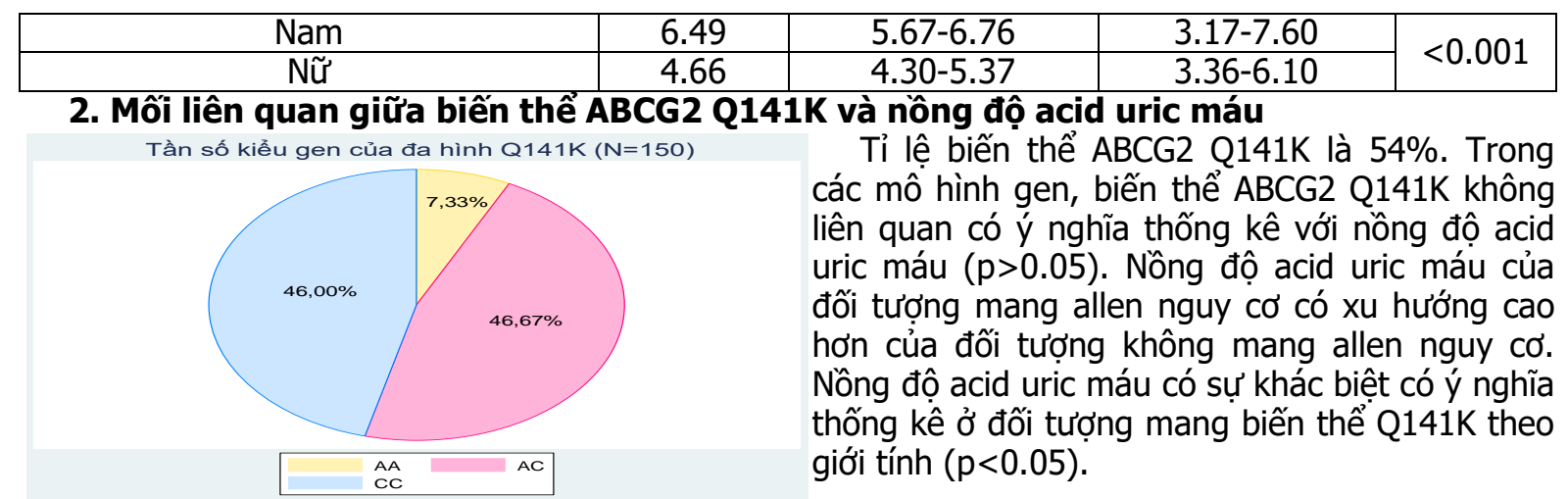

\begin{tabular}{|c|c|c|c|c|c|}
\hline \multirow{2}{*}{ Q141K } & \multirow{2}{*}{$\begin{array}{l}\text { Kiểu gen } \\
\text { (n) }\end{array}$} & \multicolumn{4}{|c|}{ Nồng độ acid uric máu (mg/dl) } \\
\hline & & Giá trị trung vị & Khoảng $25^{\text {th }}-75^{\text {th }}$ & Min - Max & Giá trị p \\
\hline \multirow{3}{*}{ Cộng gộp } & $\mathrm{AA}(11)$ & 5.20 & $4.55-5.69$ & $4.34-6.76$ & \multirow{3}{*}{0.272} \\
\hline & $\mathrm{AC}(70)$ & 5.30 & $4.52-5.89$ & $3.38-7.60$ & \\
\hline & CC (69) & 4.84 & $4.30-5.67$ & $3.17-6.99$ & \\
\hline \multirow{2}{*}{ Lặn } & AA (11) & 5.20 & $4.55-5.69$ & $4.34-6.76$ & \multirow{2}{*}{0.754} \\
\hline & $A C+C C(139)$ & 5.09 & $4.37-5.83$ & $3.17-7.60$ & \\
\hline \multirow{2}{*}{ Trội } & $\mathrm{AA}+\mathrm{AC}(81)$ & 5.30 & $4.52-5.88$ & $3.38-7.60$ & \multirow{2}{*}{0.107} \\
\hline & CC (69) & 4.84 & $4.30-5.67$ & $3.17-6.99$ & \\
\hline \multirow{2}{*}{ Đồng trội } & $\mathrm{AA}+\mathrm{CC}(80)$ & 4.86 & $4.35-5.68$ & $3.17-6.99$ & \multirow{2}{*}{0.149} \\
\hline & AC (70) & 5.30 & $4.52-5.89$ & $3.38-7.60$ & \\
\hline Nam & \multirow{2}{*}{$\mathrm{AA}+\mathrm{AC}(81)$} & 6.54 & $6.37-6.76$ & $4.29-7.60$ & \multirow{2}{*}{0.000} \\
\hline Nữ & & 4.84 & $4.34-5.50$ & $3.38-6.10$ & \\
\hline
\end{tabular}

\section{BÀN LUÂ̂N}

ABCG2 Q141K là biến thể thường gặp ở dân số Châu Á theo các nghiên cứu trước, cũng tương đồng với nghiên cứu này trên dân số Việt Nam. ABCG2 Q141K được nhiều nghiên cứu báo cáo có liên quan nồng độ acid uric máu, tăng nguy cơ tăng acid uric máu. Tuy nhiên, trong nghiên cứu này, chúng tôi không ghi nhận mối liên quan giữa $A B C G 2$ Q141K và nồng độ acid uric máu. Kết quả này có thể do cõ̃ mẩu nghiên cứu còn hạn chế, bên cạnh đó, ngoài yếu tố di truyền, nồng độ acid uric máu còn chịu tác động từ các yếu tố môi trường như tuổi, giới tính, lối sống, điều kiện kinh tế, trình độ học vấn.

Nghiên cứu này có một số hạn chế là chúng tôi tiếp cận đối tượng nghiên cứu tại một khoa của một bệnh viện, chưa khảo sát được đối tượng thuộc nhiều vùng miền của Việt Nam. Hơn nữa, chưa có nhiều nghiên cứu tương đồng trên dân số Việt Nam để chúng tôi so sánh.

\section{KẾT LUẬN}

Không có mối liên quan giữa biến thể $A B C G 2$ Q141K và nồng độ acid uric máu ở người Việt Nam trưởng thành. Cần tiến hành các nghiên cứu với cỡ mẫu lớn hơn, mở rộng phạm vi nghiên cứu tại nhiều địa phương để khảo sát sự ảnh hưởng của biến thể ABCG2 Q141K đến nồng độ acid uric máu trên dân số Việt Nam, từ đó, hô̂ trợ công tác tư vấn di truyền, phân tầng nguy cơ sớm, giảm gánh nặng bệnh tật, chi phí điều trị.

\section{TÀI LIẸU THAM KHẢO}

1. Benn CL, Dua $\mathbf{P}$, Gurrell $R$, et al. Physiology of Hyperuricemia and Urate-Lowering Treatments. Front. Med. 2018;5:160. doi:10.3389/ fmed.2018.00160

2. Chen L, Manautou JE, Rasmussen TP, et al. Development of precision medicine approaches based on inter-individual variability of BCRP/ ABCG2. Acta Pharmaceutica Sinica B. 2019;9(4):659-674. doi:10.1016/ j.apsb. 2019.01.007

3. Reginato AM, Mount DB, Yang $I$, et al. The genetics of hyperuricaemia and gout. Nat Rev Rheumatol. doi:10.1038/nrrheum.2012.144

4. Higashino $T$, Takata $T$, Nakaoka $H$, et al. Multiple common and rare variants of ABCG2 cause gout. RMD Open. 2017;3:e000464. doi:10.1136/rmdopen-2017-000464

5. Do MD, Pham DV, Le LP, et al. Recurrent PROC and novel PROS1 mutations in Vietnamese patients diagnosed with idiopathic deep venous thrombosis. International Journal of Laboratory Hematology. 2021;43(2):266-272. doi:10.1111/ijlh.13345

6. Do MD, Mai TP, Do AD, et al. Risk factors for cutaneous reactions to allopurinol in Kinh Vietnamese: results from a case-control study.

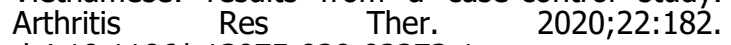
doi:10.1186/s13075-020-02273-1 
7. Mai P-T, Le D-T, Nguyen T-T, et al. Novel GDAP1 Mutation in a Vietnamese Family with Charcot-Marie-Tooth Disease. BioMed Research International. 2019;6. doi:10.1155/2019/7132494
8. Chen S-T, Wu S, Su $C$, et al. Association of ABCG2 rs2231142-A allele and serum uric acid levels in male and obese individuals in a Han Taiwanese population. J Formos Med Assoc. 2017; 116(1):18-23. doi:10.1016/j.jfma.2015.12.002

\section{KHẢO SÁT MộT SỐ YẾU TỐ LIÊN QUAN ĐẾN TÍNH CHẤT TÂN SẢN HOĂC ÁC TÍNH CỦA POLYP TÚI MÂTT}

\section{TÓM TẮT}

Muc tiêu: Khảo sát mô̂t số yếu tố liên quan đến tính chất tân sản hoặc ác tính của polyp túi mật. Phương pháp: Nghiên cứu mô tả cắt ngangtrên 95 bệnh nhân được phát hiện có polyp túi mật trên bệnh phẩm cắt túi mât tai bệnh viên Đai hoc Y Hà Nồi tù 01/2019 đến 10/2019. Kết quả: Tỉ lệ tân sản và tỉ lệ ung thư ở những trường hợp có trên 01 polyp và polyp kích thước dưới $10 \mathrm{~mm}$ thấp hơn các tỉ lệ tương ứng ở những trường hợp chỉ có 01 polyp và polyp kích thước từ $10 \mathrm{~mm}$ trở lên; tỉ lệ polyp ung thư ở những người từ 50 tuổi trở xuống thấp hơn tỉ lệ tương ứng ở những người trên 50 tuổi. Những sự khác biệt trên đều có ý nghĩa thống kê với $p<0,05$. Kết luận: Trên 50 tuổi, polyp kích thước từ $10 \mathrm{~mm}$ trở lên, chỉ có 01 polyp là các yếu tố có liên quan đến tính chất tân sản hoặc ác tính của polyp túi mâtt.

Tư khoá: Polyp túi mật, tân sản, ác tính

\section{SUMMARY}

INVESTIGATE SEVERAL FACTORS

\section{ASSOCIATED WITHNEOPLASTIC OR}

MALIGNANTGALLBLADDER POLYPS

Purpose: Investigate several factors associated with neoplastic or malignant gallbladder polyps. Methods: A descriptive cross-sectional study was conducted on 95 patients with gallbladder polyps on cholecystectomy specimens at Hanoi Medical University Hospital from January 2019 to October 2019. Results: The rates of neoplastic polyps and cancerous polyps in cases with more than one polyp and polyps less than $10 \mathrm{~mm}$ in size were significantly lower than the figures for cases with only 1 polyp and polyps of $10 \mathrm{~mm}$ or more. The rate of cancerous polyps of those aged 50 and younger was lower than that of those over 50 years old. These differences were statistically significant with $p<0.05$. Conclusions: Over the age of 50 , polyps of $10 \mathrm{~mm}$ or more in size, only 01 polyp are factors associated with

\section{${ }^{1}$ Trường Đại học Y Hà Nội}

2Bênh viên Đai hoo Y Hà Nôi

Chịu trách nhiệm chính: Nguyễn Thị Quỳnh

Email: quynh95hmu@gmail.com

Ngày nhận bài: 15.9.2021

Ngày phản biên khoa họ: 12.11.2021

Ngày duyệt bài: 23.11.2021
Đào Thị Luận ${ }^{1,2}$, Đặng Đức Thịnh ${ }^{1,2}$, Nguyễn Thị Quỳnh ${ }^{1}$, Trần Ngọc Minh ${ }^{1,2}$ neoplastic or malignant gallbladder polyps.

Keywords: Gallbladder polyps, neoplastic, malignant

\section{I. ĐĂT VẤN ĐỀ}

Polyp túi mật là tổn thương dạng lồi do sự phát triển, tăng sinh không bình thường, nhô lên từ bề mặt niêm mạc túi mật. Tỉ lệ gặp polyp túi mật được báo cáo trong y văn thay đổi từ 1,3\% đển $6,9 \%$ cho cả hai giới trên tất cả các trường hợp cắt túi mật. Bệnh gặp ở cả 2 giới mặc dù không có sự ưu thế rõ rệt ở giới nào và ở nhiều lứa tuổi, tuy nhiên rất hiếm ở trẻ em. ${ }^{1}$ Về bản chất mô bệnh học, polyp túi mật có thể phân làm hai loại chính là tổn thương tân sản thực sự và tổn thương không phải tân sản. Tại Bệnh viện Đại học Y Hà Nội, thống kê mỗi tháng có khoảng 40-60 ca phẫu thuật cắt polyp túi mật, tuy nhiên thực tế chưa có nghiên cứu nào tại đây về đặc điểm mô bệnh học cũng như các yếu tố nguy cơ ác tính hóa của polyp túi mật để giúp định hướng điều trị và tiên lượng bệnh một cách đầy đủ. Vì vậy, chúng tôi tiến hành nghiên cứu nhằm mục tiêu: Khảo sát một số yếu tố liên quan đến tính chất tân sản hoặc ác tính của polyp túi mật.

\section{II. ĐỐI TƯỢNG VÀ PHƯƠNG PHÁP NGHIÊN CỨU}

Đối tượng nghiên cứu. Gồm 95 người bệnh được phát hiện có polyp túi mật trên bệnh phẩm cắt túi mật tại bệnh viện Đại học Y Hà Nội từ 01/2019 đến 10/2019.

\section{Tiêu chuẩn lựa chọn}

- Người bệnh được chẩn đoán có polyp túi mật trên kết quả giải phẫu bệnh bệnh phẩm phẫu thuật.

- Có đủ tiêu bản mô bệnh học và khối nến.

- Có hồ sơ bệnh án đủ các biến số cần thiết cho nghiên cứu.

Tiêu chuẩn loại trừ. Người bệnh không thoả mãn một trong các tiêu chuẩn lựa chọn trên.

Thời gian và địa điểm nghiên cứu

- Thời gian: từ 07/2020 đến 07/2021.

- Địa điểm: Khoa Giải phẫu bệnh - Bệnh viện 